\title{
Enfermidades do sistema digestório de bovinos da região semiárida do Brasil $^{1}$
}

\author{
Ana L.A. Marques ${ }^{2}$, Gildeni M.N. Aguiar², Milena A.A. Lira², Eldinê G. Miranda Neto², \\ Sérgio S. Azevedo ${ }^{2 *}$ e Sara V.D. Simões ${ }^{2}$
}

\begin{abstract}
Marques A.L.A., Aguiar G.M.N., Lira M.A.A., Miranda Neto E.G., Azevedo S.S. \& Simões S.V.D. 2018. [Digestive diseases of cattle from the semiarid of Brazil.] Enfermidades do sistema digestório de bovinos da região semiárida do Brasil. Pesquisa Veterinária Brasileira 38(3):407-416. Unidade Acadêmica de Medicina Veterinária, Centro de Saúde e Tecnologia Rural, Universidade Federal de Campina Grande, Av. Universitária s/n, Cx. Postal 61, Santa Cecília, Patos, PB 58700-970, Brazil. E-mail: sergio@vps.fmvz.usp.br

Digestive problems are important causes of diseases in cattle and studies on the frequency of its occurrence in the semiarid region of Brazil have not been conducted. The aim of this study was to acquire information on the occurrence of digestive diseases of cattle attended at the Veterinary Hospital of the Federal University of Campina Grande from January 2000 to December 2014. During the period of the survey 1,202 cattle were attended, from which $19.4 \%(233 / 1202)$ were diagnosed with digestive disorders. The lethality rate of the diseases was $49.8 \%(116 / 233)$. Traumatic reticulitis and vagal indigestion were diagnosed respectively in 13.3\% e 5.1\% of the animals treated being considered common and high lethality motor disorders, which were attributed to the severity of injuries, delay in the clinical care and inaccurate diagnoses. Obstruction of the intake flow, caused by esophageal obstruction (4.3\%), rumen impactations (11.7\%), omasum and/or abomasum impaction (3.4\%), and especially intestinal accidents (26.2\%) was a commonly identified condition, and its case totality exceeded the number cases of ruminorreticular cavity fermentative disorders. Actinobacillosis (6.9\%), actinomycosis (3\%) and paratuberculosis (1.7\%) were the bacterial infectious diseases diagnosed, and the first was the most frequent. Viral infectious diseases diagnosed were malignant catarrhal fever (4.3\%), bovine viral diarrhea and mucosal disease (3\%). Despite the management systems with low animal density and climatic conditions of the region do not favor the survival of gastrointestinal parasites, parasitic diseases were also important causes of morbidity in young cattle (9.4\%), suggesting that suitable control measures for those diseases have not been implemented Motor disorders of the ruminoreticular cavity, followed by intestinal obstructions and digestive infectious diseases are the most frequent digestive problems of cattle in the semi-arid region of Brazil. The ingestion of foreign bodies is one of the most serious problems in the region and intense work is needed to disseminate it on prophylactic measures. In addition, measures for the control and prophylaxis of infectious diseases such as bovine viral diarrhea and paratuberculosis need to be disclosed, due to the possibility of dissemination of these diseases in the herds of the region.
\end{abstract}

INDEX TERMS: Cattle, semiarid, digestive diseases, digestive system, clinics.

RESUMO.- Os problemas digestivos são importantes causas de afecções em bovinos e estudos sobre a frequência de ocorrência destas na região semiárida do Brasil ainda não

\footnotetext{
${ }^{1}$ Recebido em 3 de março de 2016.

Aceito para publicação em 31 de janeiro de 2017.

${ }^{2}$ Programa de Pós-Graduação em Medicina Veterinária, Universidade Federal de Campina Grande (UFCG), Avenida Universitária, Bairro Santa Cecília, Patos, PB 58700-970, Brasil. *Autor para correspondência: sergio@vps.fmvz.usp.br
}

foram realizados. Objetivou-se com este trabalho obter informações sobre a ocorrência de doenças do sistema digestório em bovinos atendidos no Hospital Veterinário da Universidade Federal de Campina Grande no período de janeiro de 2000 a dezembro de 2014 . No período do levantamento foram atendidos 1.202 bovinos, sendo $19,4 \%$ (233/1202) diagnosticados com enfermidades do sistema digestório. A taxa de letalidade das enfermidades foi 49,8\% (116/233). As reticulites traumáticas e a indigestão 
vagal foram diagnosticadas, respectivamente, em 13,3\%e $5,1 \%$ dos animais atendidos, sendo considerados distúrbios motores frequentes e de alta letalidade devido à gravidade das lesões, demora no atendimento clínico e imprecisão no diagnóstico. A obstrução ao fluxo da ingesta foi também uma condição identificada frequentemente, sendo ocasionada por obstruções esofágicas $(4,3 \%)$, impactações no rúmen $(11,7 \%)$, omaso e/ou abomaso $(3,4 \%)$ e principalmente acidentes intestinais $(26,2 \%)$, tendo a totalidade dos casos superado os distúrbios fermentativos da cavidade ruminorreticular. Actinobacilose (6,9\%), actinomicose (3\%) e paratuberculose $(1,7 \%)$ foram as doenças infecciosas bacterianas diagnosticadas. As doenças infecciosas virais diagnosticadas foram a febre catarral maligna $(4,3 \%)$, diarreia viral bovina e a doença das mucosas (3\%). As doenças parasitárias foram também importantes causas de morbidade em bovinos jovens $(9,4 \%)$ apesar dos sistemas de criação com baixa lotação e as condições climáticas da região não favorecerem a sobrevivência de parasitos gastrintestinais, demonstrando que não estão sendo implantadas medidas de controle adequadas para estas enfermidades. Os distúrbios motores da cavidade ruminorreticular, seguido das obstruções intestinais e das doenças infecciosas digestivas são os mais frequentes problemas digestivos de bovinos na região semiárida do Brasil. A ingestão de corpos estranhos é um dos mais graves problemas na região sendo necessário intenso trabalho de divulgação sobre medidas profiláticas. Além disso, medidas de controle e profilaxia de enfermidades infectocontagiosas como a diarreia viral bovina e a paratuberculose precisam ser divulgadas, pela possibilidade de disseminação destas nos rebanhos da região.

TERMOS DE INDEXAÇÃO: Enfermidades do sistema digestório, bovinos, semiárido, Brasil, afecções do sistema digestório, clínica.

\section{INTRODUÇ̃̃o}

Os problemas digestivos são frequentes em bovinos e, na sua maioria, estão relacionados a um inadequado manejo nutricional, seja pelo fornecimento de nutrientes em excesso, observado principalmente em sistemas intensivos de criação, ou devido ao fornecimento de alimentos em quantidade ou qualidade inadequada, situação mais observada em sistemas extensivos de criação em condições de escassez de forragens. Estas situações predispõem os animais à ocorrência de doenças metabólicas e digestivas (Lima et al. 2008, Gheller et al. 2010, Burns et al. 2013).

No estado de Pernambuco, na Clínica de Bovinos de Garanhuns/UFRPE, as enfermidades digestivas foram responsáveis por $20 \%$ da casuística (Silva Filho et al. 2012), e na região ainda foram publicados outros trabalhos identificando casos de compactação e deslocamento abomasal (Câmara et al. 2009, Câmara et al. 2010), dilatação de ceco (Silva et al. 2014), timpanismo espumoso (Coutinho et al. 2009) e obstrução intestinal (Silva Filho et al. 2011). Entre os anos de 2003 e 2007, Almeida (2008) realizou um estudo sobre as principais afecções de bovinos atendidos no Hospital Veterinário da Universidade Federal de Campina Grande (HV-UFCG), Estado da Paraíba, onde identificou-se que as afecções digestivas foram a segunda maior casuística, com frequência de 14,3\% (73/508). Na mesma região a frequência de ocorrência e a identificação dos distúrbios digestivos de caprinos e ovinos foram estudados
(Lira et al. 2013), porém ainda não foram realizados estudos semelhantes que envolvam a epidemiologia e a ocorrência de doenças digestivas em bovinos.

Estudos retrospectivos baseados na coleta de dados em arquivos são importantes em Medicina Veterinária, pois permitem agrupar dados sobre diferentes enfermidades (Fighera 2008), reconhecer as enfermidades mais frequentes, além de fornecer subsídios para a instituição de medidas profiláticas adequadas. Neste contexto, considerando que há diversos anos o HV-UFCG estabelece diagnósticos de enfermidade de bovinos procedentes de diversos estados da região Nordeste, objetivou-se com este trabalho obter informações sobre a ocorrência, aspectos clinico-patológicos e epidemiológicos das doenças digestivas de bovinos.

\section{MATERIAL E MÉTODOS}

0 trabalho foi desenvolvido a partir do levantamento de fichas da Clínica Médica de Grandes Animais (CMGA) e do Laboratório de Patologia Animal (LPA) do HV da UFCG, referentes aos atendimentos e necropsias realizados no período de 2000 a 2014. Foram coletados dados referentes à identificação e manejo dos animais, histórico dos casos, sinais clínicos, protocolos de tratamento, achados de necropsias e histopatológicos. Os animais foram examinados de acordo com a metodologia proposta por Feitosa (2016). Para o diagnóstico de enfermidades que necessitaram de testes sorológicos, isolamento e/ou identificação de agentes que não estavam inclusos na rotina do HV, amostras foram encaminhadas para laboratórios de outras instituições, como o Laboratório de Virologia da Universidade Federal do Rio Grande do Sul.

Os procedimentos cirúrgicos realizados como laparotomia, correção de acidentes intestinais e deslocamento abomasal seguiram metodologia apresentada por (Hendrickson 2010).

As enfermidades diagnosticadas foram inicialmente classificadas em grupos definidos como: distúrbios da cavidade ruminorreticular, doenças infecciosas, doenças intestinais obstrutivas, doenças parasitárias, doenças intestinais inespecíficas, afecções do abomaso, esôfago e doenças do peritônio. Posteriormente as enfermidades foram apresentadas individualmente, de acordo com a frequência de ocorrência, para facilitar a visualização das mais frequentes.

O modelo estatístico empregado no estudo foi o analítico descritivo, com a determinação do número absoluto de casos e respectiva frequência, bem como a taxa de letalidade, tanto para os grupos de enfermidades quanto para as enfermidades específicas.

\section{RESULTADOS E DISCUSSÃO}

No período do levantamento foram atendidos no Hospital Veterinário 1.202 bovinos, sendo 19,4\% (233/1202) diagnosticados com enfermidades do sistema digestório. A taxa de letalidade das enfermidades foi 49,8\% (116/233). Os grupos de enfermidades e a frequência de ocorrência de cada uma delas estão apresentados, respectivamente, nos Quadros 1 e 2.

0 grupo de enfermidades em que houve o maior número de casos foi o referente aos distúrbios motores da cavidade ruminorreticular, sendo a reticulite traumática, a indigestão vagal e a compactação de rúmen os distúrbios motores mais frequentes (Quadro 2). Dos 43 casos de reticulite diagnosticados em três houve o envolvimento apenas do retículo, em nove do retículo e peritônio e em 31 casos do retículo, peritônio e pericárdio. Nos casos de reticulite 
Quadro 1. Grupos de enfermidades digestivas diagnosticadas em bovinos atendidos no Hospital Veterinário da Universidade Federal de Campina Grande no período de janeiro de 2000 a dezembro de 2014

\begin{tabular}{|c|c|c|c|c|}
\hline \multirow{2}{*}{ Grupos de enfermidades } & \multirow{2}{*}{ Número de casos } & \multirow{2}{*}{ Frequência (\%) } & \multicolumn{2}{|c|}{ Letalidade } \\
\hline & & & $\mathrm{N}$ & $\%$ \\
\hline Distúrbios motores da cavidade ruminorreticular & 59 & 25,3 & 47 & 79,7 \\
\hline Doenças infecciosas & 44 & 18,9 & 21 & 47,7 \\
\hline Doenças intestinais obstrutivas & 42 & 18 & 20 & 47,6 \\
\hline Distúrbios fermentativos da cavidade ruminorreticular & 23 & 9,9 & 04 & 17,4 \\
\hline Doenças parasitárias & 22 & 9,4 & 06 & 27,3 \\
\hline Diarreia sem etiologia específica & 19 & 8,1 & 06 & 31,6 \\
\hline Afecções do abomaso & 11 & 4,7 & 06 & 54,5 \\
\hline Afecções do esôfago & 11 & 4,7 & 04 & 36,3 \\
\hline Doenças do peritônio & 02 & 0,8 & 02 & 100 \\
\hline
\end{tabular}

Quadro 2. Afecções digestivas diagnosticadas em bovinos atendidos no Hospital Veterinário da Universidade Federal de Campina Grande, Patos/Paraíba, no período de janeiro de 2000 a dezembro de 2014

\begin{tabular}{|c|c|c|c|c|}
\hline \multirow{2}{*}{ Enfermidades } & \multirow{2}{*}{ Número de casos } & \multirow{2}{*}{ Frequência (\%) } & \multicolumn{2}{|c|}{ Letalidade } \\
\hline & & & $\mathrm{N}$ & $\%$ \\
\hline Reticulopericardite traumática & 31 & 13,3 & 31 & 100 \\
\hline Parasitoses gastrintestinais & 22 & 9,4 & 06 & 27,3 \\
\hline Diarreia sem etiologia específica & 19 & 8,1 & 06 & 31,6 \\
\hline Actinobacilose & 16 & 6,9 & 00 & 00 \\
\hline Indigestão simples & 14 & 6,0 & 00 & 00 \\
\hline Indigestão vagal & 12 & 5,1 & 09 & 75 \\
\hline Intussuscepção & 12 & 5,1 & 08 & 66,7 \\
\hline Eventração & 12 & 5,1 & 03 & 25 \\
\hline Febre Catarral Maligna & 10 & 4,3 & 09 & 90 \\
\hline Obstruções esofágicas & 10 & 4,3 & 04 & 40 \\
\hline Reticuloperitonite traumática & 09 & 3,9 & 07 & 77,8 \\
\hline Compactação abomasal & 08 & 3,4 & 04 & 50 \\
\hline Doença das Mucosas/ Diarreia Viral Bovina & 07 & 3,0 & 07 & 100 \\
\hline Actinomicose & 07 & 3,0 & 01 & 14,3 \\
\hline Obstruções intestinais por fitobezoar & 06 & 2,6 & 01 & 16,7 \\
\hline Compactação ruminal & 04 & 1,7 & 00 & 0 \\
\hline Torção intestinal & 04 & 1,7 & 04 & 100 \\
\hline Paratuberculose & 04 & 1,7 & 04 & 100 \\
\hline Acidose ruminal & 03 & 1,3 & 03 & 100 \\
\hline Reticulite traumática & 03 & 1,3 & 00 & 00 \\
\hline Ruminite & 03 & 1,3 & 01 & 33,3 \\
\hline Compactação do cólon & 03 & 1,3 & 02 & 66,7 \\
\hline Prolapso retal & 02 & 0,8 & 00 & 00 \\
\hline Dilatação cecal & 02 & 0,8 & 01 & 50 \\
\hline Timpanismo espumoso & 02 & 0,8 & 00 & 00 \\
\hline Úlcera de abomaso & 02 & 0,8 & 02 & 100 \\
\hline Peritonite & 02 & 0,8 & 02 & 100 \\
\hline Traumatismo esofágico & 01 & 0,4 & 00 & 00 \\
\hline Deslocamento abomasal & 01 & 0,4 & 00 & 00 \\
\hline Estenose do cólon & 01 & 0,4 & 01 & 100 \\
\hline Indigestão do final da prenhez & 01 & 0,4 & 00 & 00 \\
\hline
\end{tabular}

não houve óbito, sendo a letalidade $77,8 \%$ nos casos de retículo-peritonite e $100 \%$ em casos de retículo-pericardite traumática. Em apenas 12 casos foi possível identificar o corpo estranho, nos demais foram encontradas cicatrizes da perfuração, aderências e abscessos. Os corpos estranhos metálicos foram encontrados principalmente durante as necropsias e consistiam em grampos de cerca ou pregos e arames com 5 a $20 \mathrm{~cm}$ de comprimento. A não identificação do o agente causador da lesão depende do tempo de sua ingestão, em alguns casos o corpo estranho pode perfurar, 
causar a lesão e se desprender, podendo voltar para dentro do retículo, desintegrar-se ou mesmo progredir até ser eliminado do trato intestinal (Barker et al. 1993). Oliveira et al. (2013) ao estudarem casos de reticulopericardite em abatedouros observaram que 74\% dos animais apresentavam perfuração do saco pericárdico e aderências reticulares, porém em somente $34 \%$ foi possível a visualização dos corpos estranhos.

As perfurações do retículo por corpo estranho, por estarem entre as doenças mais comuns de bovinos são, há vários anos, enfermidades que preocupam médicos veterinários (Mousavi et al. 2007). Geralmente associa-se a enfermidade ao acesso dos animais a lixões. No entanto, entre os animais acometidos apenas um teve histórico de acesso a lixões, demonstrando que a ingestão dos corpos estranhos pode ter ocorrido nas áreas de pastejo ou durante a ingestão de alimentos fornecidos em cochos de madeira ou borracha com manutenção insatisfatória, situação bastante frequente na região.

A alta letalidade observada nos casos de reticuloperitonite e reticulopericardite foi atribuída à gravidade das lesões, demora no atendimento clínico e imprecisão no diagnóstico. A conclusão de que houve demora no atendimento e imprecisão no diagnóstico foi obtida durante avaliação do histórico dos casos, pois em 41,9\% (18/43) destes havia relatos de que os animais foram previamente diagnosticados como portadores de outras enfermidades como indigestões simples, tristeza parasitária ou hipocalcemia. Após o estabelecimento inicial destes diagnósticos os animais foram submetidos a tratamentos nas propriedades e houve remissão parcial dos sinais, porém posteriormente voltaram a adoecer. É provável que os primeiros sinais dos animais já estivessem relacionados à reticulite traumática, porém não foram prontamente realizados os procedimentos de laparorruminotomia exploratória, medida diagnóstica e terapêutica mais adequada aos casos. Nos três casos diagnosticados como reticulite houve recuperação dos animais, sendo possível identificar, durante laparorruminotomia, que não havia presença de aderências na cavidade, sendo o corpo estranho identificado e retirado do retículo antes que causasse maiores danos. Nos nove animais, em que o envolvimento do peritônio foi identificado também durante exploração da cavidade abdominal o histórico do caso demonstrava que houve demora entre o início dos sinais clínicos e a realização do procedimento cirúrgico.

Considerando as dimensões dos corpos estranhos encontrados pode-se considerar que a sua visualização seria possível no caso de uma fiscalização mais intensa. É necessário que proprietários e tratadores sejam devidamente alertados e adotem outra postura em relação à profilaxia dessas doenças, que deve incluir a limpeza dos currais, busca por corpos estranhos junto aos alimentos fornecidos em cochos e a manutenção das cercas e dos cochos de madeiras e de pneus que são frequentemente utilizados na região.

A indigestão vagal (IV) foi outro distúrbio motor identificado com relativa frequência, sendo o segundo mais frequente. Os diagnósticos dos casos foram concluídos após a identificação de sinais clínicos sugestivos da enfermidade. Os sinais clínicos identificados nos animais variavam em decorrência da estenose funcional ser anterior ou posterior. Porém a anorexia, desidratação de moderada a grave, distensão abdominal e a perda de estratificação ruminal puderam ser observados em todos os casos. A prova de atropina foi positiva em todos os animais que apresentavam bradicardia, sendo a hipermotilidade ruminal frequentemente identificada nos animais bradicárdicos. A elevação dos níveis de cloreto no suco ruminal era frequente nos casos em que era confirmada a compactação abomasal, identificada através da palpação de abomaso distendido e firme em laparoruminotomia exploratória. Um dos animais apresentou tosse associada à regurgitação em jatos do conteúdo ruminal e durante laparorruminotomia foi observada ausência de tônus no orifício retículo-omasal, e aumento de volume do omaso, que também estava firme (sem deixar impressão digital) sugerindo estar compactado. De acordo com Radostits et al. (2002) a compactação do omaso ocorre esporadicamente como parte da síndrome da indigestão vagal, mas sua causa é incerta.

A identificação de aderências durante realização de laparotomias ou necropsias também orientaram os diagnósticos de indigestão vagal. As aderências estavam localizadas entre diversos órgãos e estruturas como retículo e diafragma, omaso e diafragma, baço e retículo ou abomaso e peritônio, sugerindo que o quadro foi desencadeado pelo envolvimento de ramos do nervo vago nestes processos inflamatórios ou mesmo pela presença da aderência. Segundo Radostits et al. (2002) as aderências por si só podem causar a diminuição mecânica da motilidade reticular, causando desequilíbrio entre o tempo de retenção das partículas e o seu fluxo no complexo ruminorreticular, alterando o trânsito normal dos alimentos.

Em dois casos de IV foi identificado corpo estranho perfurante na área de aderência situada entre omaso, retículo e diafragma, em outro caso também foi identificado corpo estranho metálico posicionado na região pilórica, além da presença de um abscesso entre o abomaso e retículo, demonstrando a associação existente entre a reticulopericardite traumática e a indigestão vagal. De acordo com Rehage et al. (1995) as reticulopericardites traumáticas são consideradas as enfermidades que mais predispõem a lesões que originam a indigestão vagal. A comprovação da associação entre abscessos e aderências na cavidade abdominal, decorrentes de reticulites traumáticas, reforça a importância da realização de intenso trabalho de divulgação das medidas profiláticas e precisão no diagnóstico das perfurações do retículo por corpo estranho pontiagudo.

Os casos de compactações ruminais ocorreram em fêmeas com idade entre dois e sete anos de idade e estiveram associados à ingestão de forragens maduras e com baixos níveis de energia e proteína, a exemplo do capim elefante (Pennisetum purpureum). Devido à baixa qualidade das forragens estas eram fornecidas moídas e misturadas com farelos como forma de melhorar a palatabilidade, o que ocasionava a ingestão de grandes quantidades e acúmulo na cavidade ruminorreticular. Dietas de má qualidade comprometem a capacidade fermentativa da microbiota ruminal, levando ao acúmulo de alimento nos pré-estômagos e obstrução da luz visceral, impossibilitando a progressão da ingesta, que se transforma em uma massa compacta de material indigerível (Mitchell 1991, Radostits et al. 2002, Garry 2006). Os sinais clínicos mais observados foram hiporexia ou anorexia, hipomotilidade ruminal, parada da ruminação, distensão abdominal, desidratação, redução da quantidade de fezes e aumento da frequência cardíaca. Os animais foram tratados durante 5 dias com laxantes como suco de mandacarú (Cereus jamacaru) e purgante salino, fluidoterapia oral, 
10 litros diários de suco de rúmen e todos responderam de forma satisfatória ao tratamento.

As doenças infecciosas foram o segundo grupo de enfermidades em que ocorreram os maiores números de casos, sendo a actinobacilose, actinomicose e a paratuberculose as enfermidades bacterianas diagnosticadas mais frequentemente. A maioria dos animais com actinobacilose era criada em regime extensivo, alimentava-se de pasto nativo e tinha idade muito variável (entre um e 13 anos). 0 período de maior ocorrência da enfermidade foi entre os meses de maio a janeiro $(11 / 16)$. Um dos animais apresentou a forma clássica da enfermidade, sendo observada glossite difusa e protrusão da língua. Os outros apresentaram a forma atípica, sendo identificados granulomas na mandíbula, narinas e lábio, além de linfadenite envolvendo principalmente os linfonodos retrofaríngeos, parotídeos e submandibulares. A actinomicose, osteomielite causada pelo Actinomyces bovis, cuja lesão clássica é localizada na mandíbula e mais raramente na maxila (Thompson 2007), ocorreu de forma menos frequente que a actinobacilose, acometendo apenas sete bovinos com idade entre três e oito anos. 0 curso clínico desta enfermidade variou entre oito dias e seis meses e os sinais clínicos observados foram aumentos de volumes de consistência firme na face e região mandibular, imóveis, sensíveis e quentes à palpação, em alguns casos drenando secreção purulenta de odor fétido. Era comum aos animais doentes o aumento dos linfonodos submandibulares e parotídeos.

0 tratamento de ambas as afecções consistiu na drenagem dos abscessos, quando possível, seguida de sua cauterização com iodo, aplicações de iodeto de sódio por via endovenosa (70 mg/kg), antinflamatório e antibiótico. Os animais diagnosticados com actinobacilose responderam de forma mais satisfatória ao tratamento instituído. Dois animais com actinomicose tiveram indicação de abate devido à extensão e cronicidade da lesão. A ocorrência de actinobacilose e actinomicose foi observada em outros estudos referentes a enfermidades de bovinos realizados no Brasil (Lucena et al. 2010, Andreazza et al. 2013) demonstrando que a enfermidade é frequente nos rebanhos brasileiros, havendo inclusive relatos de surtos de actinobacilose (Mondadori et al. 1994, Loss et al. 2006). Durante o período do estudo não houve registros de surtos dessas enfermidades, porém observou-se que a actinobacilose ocorre de maneira relativamente frequente na região, condição provavelmente associada à ingestão de forragens grosseiras existentes no semiárido, podendo ocasionar lesões que são portas de entrada para os agentes causadores das enfermidades (Méndez \& Riet-Correa 2007).

Durante o período de levantamento foram diagnosticados quatro casos de paratuberculose, enfermidade que tem como agente etiológico o Mycobacterium avium subsp. paratuberculosis (Map) que ocasiona uma enterite granulomatosa. Os casos foram diagnosticados entre 2007 e 2014, não havendo registro da enfermidade em anos anteriores. Dois dos animais apresentaram os sinais característicos da enfermidade como diarreia, emagrecimento progressivo, diminuição do apetite e desidratação. Os diagnósticos foram confirmados através da identificação de lesões macroscópicas e histológicas, destacando-se o espessamento da mucosa do intestino delgado com áreas irregulares e enrugadas, com presença de fluido de aspecto leitoso entre as dobras da mucosa, congestão e hipertrofia das placas de Peyer e linfonodos mesentéricos.
Foi também observado a presença de infiltrado inflamatório composto por linfócitos, plasmócitos e macrófagos com formação de numerosas células gigantes de Langhans na mucosa intestinal e linfonodos mesentéricos. Em um animal foi possível detectar a presença de grande quantidade de bacilos álcool-ácido resistentes no intestino e linfonodo mesentérico, resultando positivo na técnica de Ziehl-Nielsen.

Levantamentos sorológicos através da técnica de ELISA realizados nos rebanhos de duas das propriedades onde ocorreram os casos clínicos de paratuberculose identificaram alta frequência de animais sorologicamente positivos (70,6\%). Um estudo sorológico realizado em 31 fazendas da região também identificou em fazendas sem histórico da doença a presença de anticorpos em animais de 21 destas, com frequência média de 10,8\% (Medeiros et al. 2012). Yamasaki et al. (2013) demonstrou que a paratuberculose está presente em 11 estados brasileiros, distribuídos nas cinco regiões do país, principalmente em rebanhos bovinos leiteiros. Na Paraíba, foi realizado um estudo da prevalência da paratuberculose nas mesorregiões do estado, em 480 rebanhos sendo encontrada uma prevalência de 34,5\% entre os rebanhos e de 10,7\% entre os 2504 animais amostrados (Vilar et al. 2015).

A ocorrência de casos clínicos e os resultados dos exames sorológicos realizados no estado da Paraíba demonstram que a enfermidade é importante na região e que o agente causador está se disseminado nos rebanhos e causando prejuízos econômicos. Além disso, é preocupante o fato da possibilidade do agente estar envolvido com a doença de Crohn em humanos (Slana et al. 2009), uma vez que o Map foi detectado em pacientes com a enfermidade (Naser et al. 2004). A situação torna-se ainda mais preocupante considerando a dificuldade relacionada ao diagnóstico da enfermidade, pois o cultivo bacteriano é um método impraticável para fins de diagnóstico, devido ao prolongado período de tempo necessário para isolamento do agente (Behr \& Collins 2010, Timms et al. 2011) e baixa sensibilidade do isolamento para o diagnóstico individual (Medeiros et al. 2012). Estudos recentes constataram que a PCR pode produzir resultados rápidos, inclusive para análise de "pools" de amostras para estimar a situação da infecção em um rebanho, podendo ser utilizado como diagnóstico rotineiro da paratuberculose (Yamasaki et al. 2013).

A doença infecciosa viral diagnosticada com maior frequência foi a febre catarral maligna (FCM), enfermidade causada por um Rhadinovirus da família Gammaherpesvirinae, caracterizada por linfoproliferação, inflamação e ulceração das mucosas e vasculite necrosante fibrinoide (Radostits et al. 2002, Smith 2006). Nove dos 10 casos diagnosticados apresentaram os sinais da forma cefálica ocular que incluíram anorexia, agalactia, febre, letargia, opacidade de córnea, ceratoconjuntivite, secreção ocular bilateral, fotofobia, secreção nasal purulenta, salivação e lesões erosivas nas mucosas nasal e oral. Além desses sinais, um animal apresentou hematúria e três apresentaram edema nos membros. Os sinais clínicos foram semelhantes aos registrados na literatura (Radostits et al. 2002, Lemos et al. 2005, Rech et al. 2005, Smith 2006).

Os diagnósticos de FCM foram baseados nos sinais clínicos, achados de necropsia ou histopatológicos, onde foi identificada a vasculite linfohistioplasmocítica generalizada, considerada uma lesão patognomônica ou muito característica para a doença (Brown et al. 2006). Os casos geralmente ocorrem de forma 
esporádica na região, porém há registro de um surto com alta morbidade e letalidade no início da década de 90 descrito por Macedo et al. (2007) que também relataram os casos de FCM que ocorreram entre os anos de 2000 a 2005 no HV da UFCG.

A taxa de letalidade da FCM foi de 90\% (9/10), apenas um animal da raça Sindi, com um ano de idade, após um curso clínico de 40 dias, teve remissão dos sinais e o proprietário optou por sua retirada do HV. Rech et al. (2005) ao estudarem surtos e casos esporádicos da doença no Rio Grande do Sul, observaram taxas de letalidade de 100\% em 93,3\% das propriedades estudadas. Em apenas uma, onde a doença ocorreu em forma de surto, três bovinos afetados sobreviveram, sendo a taxa de letalidade 83,3\%, indicando que a FCM em bovinos nem sempre é fatal. Ainda para estes autores, através de novas técnicas moleculares de diagnóstico, como a PCR, foi possível estabelecer que bovinos recuperados de FCM e portadores crônicos do vírus não são incomuns e que dentre as sequelas da doença está a arteriopatia obliterante crônica (O’Toole et al. 1995, 1997, Otter et al. 2002).

Embora a epidemiologia da FCM no semiárido não tenha sido estabelecida um fator de risco importante para a doença é a criação conjunta de bovinos e ovinos, que é uma característica dos sistemas de produção das propriedades da região. Porém, a enfermidade pode ocorrer também em rebanhos em que não há criação conjunta dessas duas espécies (Radostits et al. 2002, Smith 2006).

Outra enfermidade viral diagnosticada na região foi a Diarreia Viral Bovina. A identificação de sete animais com sinais clínicos da infecção pelo vírus da diarreia bovina e a comprovação em quatro destes, através de imuno-histoquimica, RT-PCR, vírus neutralização e/ou o próprio isolamento viral confirma a presença do agente na região. Nos outros três animais não foram realizados exames para comprovação da infecção viral, porém os sinais clínicos e patológicos eram sugestivos de doença das mucosas. Dois dos quatro animais comprovadamente infectados apresentaram sinais clínicos e achados patológicos característicos da doença das mucosas. Os principais sinais clínicos identificados foram hipertrofia de linfonodos pré-escapulares e pré-crurais, perda de peso progressiva, ulcerações na cavidade oral, na vulva e no reto, diarreia sanguinolenta, secreção nasal sero-mucoide bilateral, ceratoconjuntivite, dermatite generalizada com presença de crostas e desprendimento de pelo, erosões nos cascos com aumento da linha coronária e presença de crostas no boleto. Os achados patológicos mais comuns foram a presença de múltiplas erosões de tamanhos variados desde a mucosa oral até o abomaso, por vezes recobertas com conteúdo purulento. No esôfago algumas úlceras apresentavam-se lineares, em formato de arranhadura. Havia ainda atrofia de papilas bucais e ruminais, hiperplasia intestinal com evidenciação das placas de Peyer.

A presença de animais comprovadamente acometidos com a doença das mucosas é preocupante, pois esses animais são persistentemente infectados com o vírus e tem importância considerável na disseminação do agente para os demais animais do rebanho (Fulton et al. 2005). Os primeiros animais com sinais sugestivos da enfermidade foram atendidos no ano de 2007, demonstrando que o vírus pode estar se disseminando já há alguns anos. No estado da Paraíba, o primeiro levantamento sorológico realizado identificou a presença de $22 \%$ de animais sorologicamente positivos em um total de 2343 animais testados (Thompson et al. 2006). Um estudo transversal com amostragem planejada de 2443 animais de um total de 478 rebanhos, entre os anos de 2012 e 2013, também foi realizado em todo o Estado da Paraíba, obtendo-se prevalência de $65,5 \%$ de propriedades com pelo menos um animal soropositivo e 39, 1\% de animais soropositivos (Fernandes et al. 2016). Weber et al. (2014) isolaram um vírus muito semelhante ao "HoBi-like" em surto de doença respiratória no Município de Pombal, localizado no Sertão Paraibano. Ainda neste trabalho, a avaliação sorológica do rebanho através do ELISA-Ab detectou que 111 dos 123 animais testados apresentaram anticorpos contra o BVDV.

As intussuscepções, as obstruções por fitobezoares, dilatações cecais, compactação e estenose de cólon foram identificadas como causas de doenças intestinais obstrutivas. As intussuscepções foram a principal causa de obstruções no fluxo da ingesta, sendo responsável por 28,6\% (12/42) dos casos de obstrução, estando também associada a maior letalidade. Silva Filho et al. (2010) ao estudarem casos de intussuscepção em bovinos no estado de Pernambuco identificaram um percentual semelhante de casos $(26,67 \%)$. A maioria dos casos de intussuscepção, 66,7\% (8/12), ocorreu em animais adultos, e dentre os jovens nenhum apresentou sinais de enterite ou de intenso parasitismo durante os exames e necropsias realizadas, situações consideradas como fatores de risco para as intussuscepções (Constable et al. 1997). A faixa etária dos jovens acometidos variou em torno de 3 a 6 meses. Alguns autores consideram que as intussuscepções são mais comuns em bovinos com idade inferior a 2 meses (Marques et al. 2001), porém também há registros de que não há predisposição etária para esta afecção (Pearson 1971). De acordo com informações obtidas junto aos proprietários, um dos animais apresentou os sinais clínicos após a introdução da palma forrageira (Opuntia sp.) na dieta. 0 pastejo em área com sisal (Agave sisalana) também foi associado ao início dos sinais clínicos em outro animal.

Os fitobezoares, por sua vez, foram a segunda causa de obstrução intestinal, com seis casos. Apenas em 4 animais foi relatado o segmento intestinal em que houve a obstrução, sendo três no duodeno e um no jejuno. Segundo Afonso \& Costa (2007) a obstrução causada por fitobezoares ocorre quase sempre em algum segmento do duodeno ou jejuno, causando a diminuição da motilidade gastrointestinal e reduzindo a quantidade de fezes. Esta condição provoca inclusive distensão dos pré-estômagos e abomaso devido ao refluxo do conteúdo gastrointestinal. Os sinais clínicos observados nos animais foram apatia, anorexia, ausência de ruminação, cólica e distensão abdominal. As fezes estavam ausentes ou presentes em pequena quantidade, escuras e fétidas. Os achados clínicos foram semelhantes aos identificados na literatura (Dirksen 1993).

De acordo com as informações obtidas na anamnese $50 \%$ dos animais acometidos passaram a apresentar os sinais clínicos após começarem a consumir capim seco, agave e palma. Em um estudo retrospectivo no Estado de Pernambuco, 16 casos de fitobezoares estiveram relacionados à palma forrageira (Opuntia ficus indica) alimento presente na dieta de todos os animais acometidos, cuja evolução ocorreu de forma aguda (Afonso et al. 2008). Na região é comum a oferta de gramíneas e alimentos compostos por fibra de baixa digestibilidade como alternativa alimentar em épocas de seca, essa condição 
quando associada a redução na ingestão de água favorece o aparecimento desse tipo de obstrução.

Outras formas de obstruções intestinais observadas foram as torções (4 casos), dilatação de ceco (2 casos), compactação ( 3 casos) e estenose ( 1 caso) de cólon. Nos casos de torção apenas um animal era jovem (4 meses) e dentre os segmentos envolvidos estavam o ceco de um animal que também apresentou compactação do omaso, cólon e porção do intestino delgado. Em bovinos adultos acredita-se que quando há o envolvimento do ceco, a sua dilatação precede o vólvulo e a torção. A patogenia da dilatação cecal tem como principal fator a alimentação rica em carboidratos, que quando não são completamente fermentados no rúmen o são de forma excessiva no ceco, resultando em elevação da concentração dos ácidos graxos voláteis, que por sua vez, provocam a queda do pH do conteúdo cecal, causando hipotonia ou atonia, acúmulo da ingesta e gás no órgão com a consequente dilatação, deslocamento e/ou retroflexão e, em alguns casos, torção (Afonso et al. 2002, Radostits et al. 2002, Murray \& Smith 2006, Silva et al. 2014).

De uma maneira geral as obstruções intestinais não são tão comuns quanto às desordens dos pré-estômagos e abomaso (Rebhum 2000), porém os dados deste estudo demonstram que elas são a terceira causa de transtornos digestivos, superando as afecções do abomaso e os distúrbios fermentativos da cavidade ruminorreticular. Dessa forma, elas devem ser consideradas no estabelecimento do diagnóstico diferencial dos transtornos digestivos na região semiárida do Brasil, onde se observa frequentemente no histórico desses animais o registro de fornecimento de dietas de baixa digestibilidade.

Os principais distúrbios fermentativos identificados foram a indigestão simples, acidose ruminal e timpanismo espumoso. A indigestão simples foi o distúrbio fermentativo diagnosticado mais frequentemente, estando na maioria dos casos associada à modificação brusca na alimentação, conforme referenciado por Fraser et al. (1996). Dentre os alimentos ofertados aos animais que apresentaram a enfermidade havia restos de comida caseira, frutas, palha de feijão e casca de mandioca. 0 fornecimento excessivo de concentrado, aliado à ausência de forragens de boa qualidade, também foi associado a casos de indigestão. Os sinais clínicos relatados mais comumente foram apatia, anorexia, distensão abdominal, parada da ruminação e fezes pastosas. Os animais que não se recuperaram espontaneamente, o que normalmente ocorre nos casos de indigestão simples, responderam satisfatoriamente aos tratamentos instituídos que incluíram a retirada imediata do alimento suspeito ou ajustes no fornecimento, uso de laxantes, restabelecimento do equilíbrio hidroeletrolítico, transfaunações e fornecimento de volumosos de boa qualidade. Em um dos casos houve a necessidade de intervenção cirúrgica (ruminotomia), apesar de ser um caso de indigestão simples, pois houve a ingestão da placenta pela vaca. Nas avaliações do suco de rúmen foi possível observar que a maioria dos animais apresentou inatividade da flora ruminal e $\mathrm{pH}$ alcalino, cujo valor elevado justifica-se pela anorexia e a contínua produção de saliva.

A acidose ruminal e o timpanismo espumoso foram outros distúrbios fermentativos identificados, porém com ocorrência bem menor quando comparados aos casos de indigestão simples. Em outras regiões do Nordeste, a exemplo do município de Garanhuns, Estado de Pernambuco, onde há grandes bacias leiteiras e consequentemente o manejo nutricional dos animais é mais intensificado, a acidose pode representar até 10\% dos casos de distúrbios digestivos atendidos pelos veterinários (Afonso \& Mendonça 2000). Estes resultados demonstram a forte associação entre os tipos de distúrbios digestivos encontrados e o manejo alimentar ao qual os animais são submetidos nas diferentes regiões.

As doenças parasitárias foram importantes causas de morbidade em bovinos jovens, sendo identificados, através de exames coproparasitológicos, 22 casos em animais com idade entre 3 e 18 meses criados em regimes de criação extensivo e semi-intensivo. A maioria dos animais com altas cargas parasitárias tinha idade próxima a um ano. Segundo Repossi Junior et al. (2006), a faixa etária de infecções por parasitos gastrintestinais está entre 1 e 18 meses, sendo os bovinos maiores de 2 anos resistentes às parasitoses gastrointestinais (Costa et al. 1974, Charles 1992, Lima 1998, Pimentel Neto \& Fonseca 1999). 0 desenvolvimento da resposta imune do hospedeiro está associado principalmente a uma resposta prévia contra o parasito, que se torna efetiva ao redor de 18 a 24 meses. Assim, a partir dessa faixa etária, a tendência é ocorrer redução na carga parasitária, diminuição no número de ovos excretados nas fezes e baixa incidência de casos clínicos de verminose (Bresciani et al. 2001).

Apesar das características da criação desses animais no semiárido, que geralmente são mantidos em pastos com baixa lotação, e das condições climáticas da região não favorecerem a sobrevivência dos parasitos (Costa et al. 2009) os resultados demonstram que a enfermidade é uma importante causa de morbidade em animais jovens, tendo taxa de letalidade de 27,3\%. A análise das fichas clínicas dos animais demonstrou que $72,7 \%$ (16/22) destes tinham sido vermifugados, porém na maioria dos casos as vermifugações ocorreram após a manifestação dos sinais clínicos, demonstrando que o manejo antiparasitário nas propriedades é insatisfatório, pois as perdas produtivas se iniciam antes dos animais apresentarem os sinais clínicos. Delgado et al. (2009) observaram, em estudo no estado de Minas Gerais, que o critério mais frequentemente utilizado pelos proprietários, para definir o momento de utilização de anti-helmínticos em bovinos, era o início dos sinais clínicos.

A maioria dos casos de verminose atendidos (14/22) ocorreu entre o final do período chuvoso e início do período seco, fato este semelhante ao relatado por Costa et al. (2009) que observaram maior frequência de surtos de parasitoses gastrointestinais em caprinos e ovinos entre os meses de maio e agosto, sugerindo inclusive a realização de tratamentos anti-helmínticos, antes desse período crítico, pois essa medida poderia evitar surtos devido à contaminação crescente das pastagens durante o período de chuvas. Todos os demais casos ocorreram no final do período seco, o que pode estar relacionado a aspectos nutricionais. Uma adequada nutrição energética e proteica aumenta a resistência dos animais às infecções parasitárias, portanto, é importante suplementar o rebanho em períodos de escassez alimentar objetivando diminuir o grau de infecção (Torres-Acosta \& Hoste 2008).

Em estudo realizado no Rio Grande do Sul por Assis-Brasil et al. (2013) sobre as principais afecções de bovinos necropsiados com até um ano de idade os autores observaram que a partir dos seis meses as parasitoses por nematódeos gastrintestinais foram as principais enfermidades do trato digestivo, o que pode ser atribuído ao desmame, 
uma vez que os bovinos são mais susceptíveis às parasitoses nessa fase. Considerando que as condições climáticas da região semiárida, na maior parte dos meses do ano, não são favoráveis aos parasitos, as helmintoses gastrintestinais não deveriam ser um problema. A ocorrência dos casos clínicos demonstra que não estão sendo implantadas quaisquer medidas de controle adequadas para os bovinos jovens.

Dos 22 animais acometidos, somente 16 tinham anexados em seus registros exames coproparasitológicos. Em 87,5\% (14/16) das amostras fecais foram encontrados ovos da superfamília Trichostrongylidae, com mediana de 7.450 ovos por grama de fezes (OPG). Ovos dos gêneros Strongyloides foram identificados em 31,3\% (5/16) das amostras, com mediana de 500 OPG. Em 12,5\% (2/16) das amostras foram também identificados ovos do gênero Trichuris, com valor mediano de 75 OPG. Os resultados demonstraram que há um alto grau de infestação no ambiente e é necessário estabelecer um adequado programa de controle de parasitoses gastrintestinais nos rebanhos da região. Eimeria foi também identificada em 62,5\% (10/16) das amostras com mediana de 700 OPG. Alguns casos clínicos em que o principal sinal foi a diarreia, porém sem a etiologia identificada, foram considerados como diarreia sem etiologia específica. Foram 19 casos atendidos onde houveram 5 óbitos ligados à enterites necrosante, granulomatosa e linfohistiocitária e um óbito relacionado à falha na transferência de imunidade passiva.

Dentre as afecções do abomaso foram diagnosticados casos de compactações, úlceras e deslocamento. As compactações abomasais foram diagnosticadas em oito animais. Dois desses apresentaram também compactação do omaso. Os animais acometidos tinham entre um e dez anos de idade, sendo cinco fêmeas e três machos, criados sob regime extensivo e semi-intensivo, com alimentação baseada em pasto nativo, capim braquiária, capim elefante moído, capim andrequice (Leersia hexandra), rolão de milho, farelo de milho e trigo e cama de frango. Todos os casos ocorreram no período da seca, quando as forragens estão secas, com alto teor de lignina e há pouca disponibilidade de água, semelhante ao relatado por Borges et al. (2007). Câmara et al. (2009), em outro estudo constatou que de 14 casos da enfermidade, $71,4 \%$ ocorreram na estação da seca. Segundo Blikslager et al. (1995), a ingestão de grandes quantidades de forragem de baixa qualidade e a ingestão inadequada de água são as principais causas de compactação do abomaso. No Brasil, a principal causa é a ingestão de forrageiras trituradas e ricas em lignina, seguida pela ingestão de cama de frango e palha de arroz (Moscardini \& Borges 2007).

$\mathrm{Na}$ avaliação do suco ruminal de seis dos oito animais suspeitos de compactação abomasal foi identificado teor de cloreto acima de $30 \mathrm{mEq} / \mathrm{dL}$ o que demonstra a ocorrência de refluxo abomasorruminal, que geralmente ocorre quando há obstruções na passagem da ingesta do abomaso para o intestino (Dirksen 1993). 0 fato de, durante realização de laparoruminotomia, não terem sido identificadas aderências na cavidade abdominal, que poderia levar a suposição de uma compactação abomasal secundária a lesão de vago, conduziu ao estabelecimento de diagnóstico presuntivo de indigestão abomasal primária ou dietética. Dois animais, um com 12 meses e outro com três anos, possuíam histórico de distúrbios digestivos desde os oito meses e ao exame físico foi possível identificar que apresentavam distensão abdominal, perda de peso e hipermotilidade ruminal. Os animais morreram e o principal achado de necropsia foi a presença de grande quantidade de areia no abomaso. De acordo com Radostits et al. (2002) quando grande quantidade de areia é ingerida, o omaso, abomaso, intestino grosso e ceco podem tornar-se compactados. As deficiências nutricionais em bovinos aliadas à baixa seletividade dessa espécie os levam a desenvolver aberrações no apetite levando-os a ingerir corpos estranhos como madeira, pedras, areia, dentre outros (Martins et al. 2004).

As úlceras e os deslocamentos abomasais apresentaram baixa ocorrência, respectivamente $0,8 \%$ e $0,4 \%$. Tal fato está relacionado a maioria dos animais da região serem de baixa a média produção, uma vez que estas afecções ocorrem mais comumente em regimes intensivos de criação, onde os animais são mantidos em confinamento cujo exercício é limitado, predispondo à hipomotilidade abomasal, por exemplo. Outros fatores de risco estão relacionados a estas afecções, que incluem as trocas alimentares, em particular as lesões traumáticas da mucosa associada à adição de alimentos grosseiros, o estresse, desmame precoce dos bezerros, desordens neuronais e doenças metabólicas associadas à ingestão excessiva de grãos (Radostits et al. 2002).

As afecções esofágicas foram caracterizadas por obstruções (8/10) e lacerações (2/10). Quatro animais apresentaram obstrução pela ingestão da semente (caroço) de manga (Mangifera indica), uma fruta muito comum na região, que também ocasionou laceração no esôfago de um animal. A laceração esofágica também ocorreu devido a ingestão de um galho de juazeiro (Ziziphus joazeiro). 0 alto número destas afecções está relacionado ao hábito alimentar dos bovinos, que consomem grandes quantidades de alimentos de forma rápida e com baixa seletividade, sendo dentre os ruminantes a espécie mais susceptível, seguida da ovina e caprina (Borges et al. 2007). Segundo Souza et al. (2011), no Brasil, as causas mais comuns de obstrução de esôfago são as frutas (manga, laranja, jaca, abacate), os tubérculos (mandioca, batata, macaxeira) e sobras de produtos hortifrutigranjeiros. Quando as obstruções ocorrem devido à ingestão de frutas observa-se que estão relacionadas àquelas produzidas na região e à ocorrência das safras. Em estudo realizado por Souza et al. (2011), na região de Garanhuns/PE, foi possível identificar que $80 \%$ dos casos ocorreram no período de safra das frutas. Além dos processos obstrutivos decorrentes de obstrução da luz do esôfago foram também identificadas obstruções por compressão extra luminal, resultante de abscesso na região do terço médio do pescoço. Essas compressões podem estar relacionadas a afecções que cursam com aumento dos linfonodos ou traumatismos que causam abscessos.

\section{CONCLUSÕES}

Os distúrbios motores da cavidade ruminorreticular, seguido das obstruções intestinais e das doenças infecciosas digestivas são os mais frequentes problemas digestivos de bovinos na região semiárida do Brasil.

A ingestão de corpos estranhos é um dos mais graves problemas.

Tais distúrbios, portanto, devem ser considerados nos diagnósticos diferenciais das enfermidades do trato digestivo na região. 
Medidas de controle e profilaxia de enfermidades infectocontagiosas como a diarreia viral bovina e a paratuberculose precisam ser divulgadas, pela possibilidade de disseminação destas nos rebanhos da região.

\section{REFERÊNCIAS}

Afonso J.A.B. \& Costa N.A. 2007. Obstrução intestinal em bovinos, p.370-375. In: Riet-Correa F., Schild A.L., Lemos R.A.A. \& Borges J.R.J. Doenças de Ruminantes e Equideos. Vol.2. $3^{\text {a }}$ ed. Pallotti, Santa Maria. 392p.

Afonso J.A.B. \& Mendonça C.L. 2000. Distúrbios digestivos dos ruminantes. Anais V Encontro Médicos Veterinários e Zootecnistas no Nordeste (Enconvet), Aracaju, SE. (Resumo expandido)

Afonso J.A.B., Mendonça C.L., Costa N.A., Souza M.I., Simão L.C.V. \& Dantas F.R. 2002. Alterações clínicas e laboratoriais na dilatação do ceco em bovinos: análise de 10 casos. Revta Educ. Cont. 3(5):313-320.

Afonso J.A.B., Pereira A.L.L., Vieira A.C.S., Mendonça C.L., Costa N.A. \& Souza M.I. 2008. Alterações clínicas e laboratoriais na obstrução gastrintestinal por fitobezoários em bovinos. Revta Bras. Saúde Prod. Anim. 9(1):91-102.

Almeida F.C. 2008. Principais afecções de bovinos atendidos no Hospital Veterinário da Universidade Federal de Campina Grande, Campos de Patos, PB. 24p. (Monografia em Medicina Veterinária)

Andreazza D., Wouters A.T.B., Watanabe T.T.N., Boabaid F.M., Wouters F., Souza F.S. Souza S.O. \& Driemeier D. 2013. Caracterização patológica e imuno-histoquímica das lesões de actinobacilose em bovinos. Pesq. Vet. Bras. 33(3):305-309. http://dx.doi.org/10.1590/S0100-736X2013000300005.

Assis-Brasil N.D., Marcolongo-Pereira M., Hinnah F.L., Ladeira S.R.L., Sallis E.S.V., Grecco F.B. \& Schild A.L. 2013. Enfermidades diagnosticadas em bezerros na região sul do Rio Grande do Sul. Pesq. Vet. Bras. 33(4):423-430. http://dx.doi. org/10.1590/S0100-736X2013000400002.

Barker I.K., Van Dreumel A.A. \& Palmer N. 1993. The alimentary system, p.163-173. In: Jubb K.V.F., Kennedy P.C. \& Palmer N. (Eds), Pathology of Domestic Animals. Vol.2. 5th ed. Academic Press, San Diego. 747p. http://dx.doi.org/10.1016/ B978-0-12-391606-8.50009-0.

Behr M.A. \& Collins D.M. 2010. Paratuberculosis: organism, disease, control. CAB International, Cambridge. 375p. http://dx.doi.org/10.1079/9781845 936136.0000 .

Blikslager A.T., Anderson K.L., Bristol D.G., Fubini S.L. \& Anderson D.E. 1995. Abomasal impactation in cattle. J. Am. Vet. Assoc. 15:571-573.

Borges J.R.J., Cunha P.H.J., Moscardini A.R.C., Tortelly R., Franco G.L. \& Silva L.A.F. 2007. Compactação de abomaso em bovinos leiteiros: descrição de cinco casos. Ciênc. Anim. Bras. 8(4):857-862.

Bresciani K.D.S., Nascimento A.A., Costa A.J., Amarante A.F.T., Perri S.H.V. \& Lima L.G.F. 2001. Frequência e intensidade parasitária de helmintos gastrintestinais em bovinos abatidos em frigorífico da região noroeste do Estado de São Paulo, SP, Brasil. Semina, Ciênc. Agrárias 22(1):93-97.http://dx.doi.org/10.5433/16790359.2001v22n1p93.

Brown C.C., Baker D.C. \& Barker I.K. 2006. Alimentary system, p.1-296. In: Jubb K.V.F., Kennedy P.C. \& Palmer N. (Eds), Pathology of Domestic Animals. Vol.2. 5th ed. Academic Press, San Diego. 747p.

Burns L.V., Helayel M.A., Silva M.A.G., Maruo V.M., Córdova F.M., Silva S.L., Barros C.S.L. \& Ramos A.T. 2013. Doenças de animais de produção na região centronorte do Estado de Tocantins: 85 casos. Arq. Pesq. Anim. 2(1):1-6.

Câmara A.C.L., Afonso J.A.B., Costa N.A., Mendonça C.L. \& Souza M.I. 2009. Compactação primária do abomaso em 14 bovinos no Estado de Pernambuco. Pesq. Vet. Bras. 29(5):387-394. http://dx.doi.org/10.1590/S0100-736X2009000500005.

Câmara A.C.L., Afonso J.A.B., Costa N.A., Mendonça C.L., Souza M.I. \& Borges J.R.J. 2010. Fatores de risco, achados clínicos, laboratoriais e avaliação terapêutica em 36 bovinos com deslocamento de abomaso. Pesq. Vet. Bras. 30(5):453-464 http://dx.doi.org/10.1590/S0100-736X2010000500014.

Charles T.P. 1992. Verminoses dos bovinos de leite, p.55-110. In: Charles T.P. \& Furlong J. (Eds), Doenças Parasitárias dos Bovinos de Leite. Embrapa-CPGL, Coronel Pacheco, MG.
Constable P.D., St Jean G., Hull B.L., Rings D.M., Morin D.E. \& Nelson D.R. 1997. Intussusception in cattle: 336 cases (1964-1993). J. Am. Vet. Med. Assoc. 210(4):531-536. PMid:9040842.

Costa H.M.A., Guimarães M.P., Costa J.O. \& Freitas M.G. 1974. Variação estacional da intensidade de infecção por helmintos parasitos de bezerros em algumas áreas de produção leiteira em Minas Gerais. Arq. Esc. Vet. 26(1):143-153.

Costa V.M.M., Simões S.V.D. \& Riet-Correa F. 2009. Doenças parasitárias em ruminantes no semi-árido brasileiro. Pesq. Vet. Bras. 29(7):563-568. http:// dx.doi.org/10.1590/S0100-736X2009000700011.

Coutinho L.T., Afonso J.A.B., Costa N.A., Mendonça C.L., Faria P.A.R. \& Soares P.C. 2009. Avaliação da conduta terapêutica em casos de timpanismo espumoso em bovinos. Ciênc. Anim. Bras. 10(1):288-293.

Delgado F.E., Lima W.S., Cunha A.P., Bello A.C., Domingues L.N., Wanderley R.P., Leite P.V. \& Leite R.C. 2009. Verminoses dos bovinos: percepção de pecuaristas em Minas Gerais, Brasil. Revta Bras. Parasitol. Vet. 18(3):29-33. http://dx.doi. org/10.4322/rbpv.01803005. PMid:19772773.

Dirksen G. 1993. Sistema digestivo, p.164-228. In: Rosenberger R.G. (Ed.), Exame Clínico dos Bovinos. 3를. ed. Guanabara Koogan, Rio de Janeiro.

Feitosa F.L.F. 2016. Semiologia Veterinária: a arte do diagnóstico. 3를 ed. Roca, São Paulo. 640p.

Fernandes L.G., Nogueira A.H., Stefano E., Pituco E.M., Ribeiro C.P., Alves C.J., Oliveira T.S., Clementino I.J. \& Azevedo S.S. 2016. Herd-level prevalence and risk factors for bovine viral diarrhea virus infection in cattle in the State of Paraíba, Northeastern Brazil. Trop. Anim. Health Prod. 48(1):157-165. http:// dx.doi.org/10.1007/s11250-015-0937-x. PMid:26498460.

Fighera R.A. 2008. Causas de morte e razões para eutanásia em cães. Tese de Doutorado, Universidade Federal de Santa Maria, Santa Maria, RS. 171p.

Fraser C.M., Bergeron J.A., Mays A. \& Aiello S.E. 1996. Manual Merck de Veterinária: um manual de diagnóstico, tratamento, prevenção e controle de doenças para o veterinário. 7ª ed. Roca, São Paulo. 2169p.

Fulton R.W., Briggs R.E., Ridpath J.F., Saliki J.T., Confer A.W., Payton M.E., Duff G.C., Step D.L. \&Walker D.A. 2005. Transmission of bovine viral diarrhea virus $1 \mathrm{~b}$ to susceptible and vaccinated calves by exposure to persistently infected calves. Can. J. Vet. Res. 69(3):161-169. PMid:16187545.

Garry F.B. 2006. Indigestão em ruminantes, p.722-747. In: Smith B.P. (Ed.), Medicina Interna de Grandes Animais. $3^{a}$ ed. Editora Manole, Barueri, SP.

Gheller L.F.M., Bueno A.V.I., Kastelijn D., Carneiro M.K. \& Marcantonio M. 2010. Perfil da população de grandes animais assistidas pela clínica escola veterinária (Cevet, Unicentro) no biênio 2008-2009 em relação às principais espécies atendidas e os sistemas acometidos. Anais XIX Encontro Anual de Iniciação Cientifica (EAIC), Universidade Estadual do Centro-Oeste, Guarapuava, PR. 4p.

Hendrickson D.A. 2010. Técnicas Cirúrgicas em Grandes Animais. 3aㅡ ed. Guanabara Koogan, Rio de Janeiro. 332p.

Lemos R.A.A., Rech R.R., Guimarães E.B., Kadri A. \& Dutra I.S. 2005. Febre catarral maligna em bovinos do Mato Grosso do Sul e de São Paulo. Ciência Rural 35(4):932-934. http://dx.doi.org/10.1590/S0103-84782005000400030.

Lima A.G., Arêas V.S., Júnior L.V., Silva P.C.A.R. \& Nunes L.C. 2008. Atendimento na rotina da clínica médica de animais de produção do hospital veterinário, UFES, entre os anos de 2004 a 2008. IXI Encontro Anual de Iniciação Científica (EAIC), Universidade Estadual do Centro-Oeste, Guarapuava, PR.

Lima W.S. 1998. Seasonal infection pattern of gastrointestinal nematodes of beef cattle in Minas Gerais State, Brazil. Vet. Parasitol. 74(2-4):203-214. http:// dx.doi.org/10.1016/S0304-4017(97)00164-7. PMid:9561708.

Lira M.A.A., Simões S.V.D., Riet-Correa F., Pessoa C.M.R., Dantas A.F.M. \& Miranda Neto E.G. 2013. Doenças do sistema digestório de caprinos e ovinos no semiárido do Brasil. Pesq. Vet. Bras. 33(2):193-198. http://dx.doi.org/10.1590/S0100736X2013000200010.

Loss D.E., Vogg G., Bandarra P.M., Raymundo D.L., Conceição E.O., Dalto A.G.C., Oliveira M.B. \& Driemeier D. 2006. Ocorrência em surto de actinobacilose em bovinos mantidos em área de capim anoni (Eragrostis plana) no Rio Grande do Sul. Anais 2 o Encontro Nacional de Laboratórios de Diagnóstico Veterinário, Campo Grande, MS, p.41-42. (Resumo) 
Lucena R.B., Pierezan F., Kommers G.D., Irigoyen L.F., Fighera R.A. \& Barros C.S.L. 2010. Doenças de bovinos no Sul do Brasil: 6.706 casos. Pesq. Vet. Bras. 30(5):428-434. http://dx.doi.org/10.1590/S0100-736X2010000500010.

Macêdo J.T.S.A., Riet-Correa F., Simões S.V.D., Dantas A.F.M. \& Nobre V.M.T. 2007. Febre catarral maligna em bovinos na Paraíba. Pesq. Vet. Bras. 27(7):277-281. http://dx.doi.org/10.1590/S0100-736X2007000700004.

Marques L.C., Cattelan J.W., Macoris D.G., Marques J.A., Portugal E.S. \& Cadioli F.A. 2001. Estudo clínico, cirúrgico e anatomopatológico de intussuscepção em quatro bovinos. Arq. Bras. Med. Vet. Zootec. 53(1):52-57. http://dx.doi. org/10.1590/S0102-09352001000100008.

Martins A.M.C.R.P.F., Leme M.C.M., Portugal M.A.S.C., Baldassi L. \& Margatho L.F.F. 2004. Presença de corpos estranhos no aparelho digestório dos bovinos. Arqs Inst. Biológico, São Paulo, 71(1):83-87.

Medeiros J.M.A., Garino Junior F., Almeida A.P., Lucena E.A. \& Riet-Correa F. 2012 Paratuberculose em caprinos e ovinos no Estado da Paraíba. Pesq. Vet. Bras 32(2):111-115. http://dx.doi.org/10.1590/S0100-736X2012000200003.

Méndez M.C. \& Riet-Correa F. 2007. Actinobacilose, p.208-213. In.: Riet-Correia F., Schild A.L., Lemos R.A.A. \& Borges J.R. (Eds), Doenças de Ruminantes e Equídeos. Pallotti, Santa Maria.

Mitchell K.J. 1991. Dietary abomasal impaction in a herd of dairyreplacement heifers. J. Am. Vet. Med. Assoc. 198(8):1408-1409. PMid:1648050.

Mondadori A.J., Riet-Correa F., Carter G.R. \& Mendez M.D.C. 1994. Actinobacilose em bovinos no Rio Grande do Sul. Ciência Rural 24(3):571-577. http://dx.doi. org/10.1590/S0103-84781994000300022.

Moscardini A.R.C. \& Borges J.R.J. 2007. Compactação de abomaso, p.352-355 In: Riet-Correia F., Schild A.L., Lemos R.A.A. \& Borges J.R. (Eds), Doenças de Ruminantes e Equídeos. Pallotti, Santa Maria.

Mousavi G., Hassanpour A., Tabrizi A. \& Rezaie A. 2007. Eletrocardiographic changes in buffalo with traumatic reticuloperitonitis. Ital. J. Anim. Sci. 6(Suppl.2):1029-1031. http://dx.doi.org/10.4081/ijas.2007.s2.1029.

Murray M.J. \& Smith B.P. 2006. Enfermidades do trato alimentar, p.293-789. In: Smith B.P. (Ed.), Medicina Interna de Grandes Animais. $3^{\text {a }}$ ed. Manole, Barueri, SP.

Naser S.A., Ghobrial G., Romero C. \& Valentine J.F. 2004. Culture of Mycobacterium avium subspecies paratuberculosis from the blood of patients with Crohn's disease. Lancet 364(9439):1039-1044. PMid:15380962.

O’Toole D., Li H., Miller D., Williams W.R. \& Crawford T.B. 1997. Chronic and recovered cases of sheep-associated malignant catarrhal fever in cattle. Vet. Rec 140(20):519-524. http://dx.doi.org/10.1136/vr.140.20.519. PMid:9178482

O’Toole D., Li H., Roberts S., Rovnak J., DeMartini J.C., Cavender J., Williams B. \& Crawford T.B. 1995. Chronic generalized obliterative arteriopathy in cattle: a sequel to sheep-associated malignant catarrhal fever. J. Vet. Diagn. Invest. 7(1):108-121.http://dx.doi.org/10.1177/104063879500700118. PMid:7779945.

Oliveira H.C., Silva L.C., Cunha Filho L.F.C., Santana E.H.W., Bogado A.L.G., Negri Filho L.C. \& Okano W. 2013. Ocorrência de reticulo pericardite traumática em bovinos de abate, na região de Araguari, MG. Revta Bras. Hig. Sanid. Anim 7(2):192-202. http://dx.doi.org/10.5935/1981-2965.20130017.

Otter A., Pow I. \& Reid H.W. 2002. Outbreak of malignant catarrhal fever in Welsh black cattle in Carmarthenshire. Vet. Rec. 151(11):321-324. http://dx.doi. org/10.1136/vr.151.11.321. PMid:12356235.

Pearson H. 1971. Intussusception in cattle. Vet. Rec. 89(16):426-437. http:// dx.doi.org/10.1136/vr.89.16.426. PMid:5167390.

Pimentel Neto M.\& Fonseca A.H.1999. Epidemiologia das helmintoses pulmonares e gastrintestinais de bovinos de leite na microrregião homogênea do Vale do Paraíba Fluminenese. Hora Vet. 19(112):41-46.

Radostits O.M., Gay C.C., Blood D.C. \& Hinchcliff K.W. 2002. Clínica Veterinária: um tratado de doenças dos bovinos, ovinos, suínos, caprinos e eqüinos. 9a ed. Guanabara Koogan, Rio de Janeiro. 1737p.

Rebhum W.C. 2000. Doenças infecciosas do trato gastrointestinal, p.205-210. In: Ibid. (Ed.), Doença do Gado Leiteiro. Roca, São Paulo.

Rech R.R., Schild A.L., Driemeier D., Garmatz S.L., Oliveira F.N., Riet-Correa F. \& Barros C.S.L. 2005. Febre catarral maligna em bovinos no Rio Grande do Sul: epidemiologia, sinais clínicos e patologia. Pesq. Vet. Bras. 25(2):97-105. http://dx.doi.org/10.1590/S0100-736X2005000200006.
Rehage J., Kaske M., Stockhofe-Zurwieden N. \& Yalcin E. 1995. Evaluation of the pathogenesis of vagus indigestion in cow with traumatic reticuloperitonitis. JAMA 207(12):1607-1611. PMid:7493901.

Repossi-Junior P.F., Barcellos M.P., Trivilin L.O., Martins I.V.F. \& Silva P.C.A.R. 2006. Prevalência e controle das parasitoses gastrintestinais em bezerros do município de Alegre, Espírito Santo. Revta Bras. Parasitol. Vet. 15(4):147150. PMid:17196117.

Silva Filho A.P., Afonso J.A.B., Riet-Correa F., Dantas A.F., Souza J.C.A., Dantas A.C., Costa N.A. \& Mendonça C.L. 2011. Obstrução intestinal por linfossarcoma em bovinos: estudo retrospectivo. Vet. Zootec. 18(2):264-274.

Silva Filho A.P., Afonso J.A.B., Souza J.C.A., Costa N.A. \& Mendonça C.L. 2010. Análise clínica e patológica em 20 casos de intussuscepção em bovinos. Vet. Zootec. 17(3):421-430.

Silva Filho A.P., Afonso J.A.B., Souza J.C.A., Dantas A.C., Costa N.A. \& Mendonça C.L. 2012. Achados clínicos de bovinos com úlcera de abomaso. Vet. Zootec. 19(2):196-206.

Silva R.J., Silva J.A.B.A., Costa N.A. \& Mendonça C.L. 2014. Dilatação do ceco em bezerros: relato de casos. Revta Bras. Ciênc. Vet., Heredia, 21(2):76-81.

Slana I., Liapi M., Moravkova M., Kralova A. \& Pavlik I. 2009. Mycobacterium avium subsp. paratuberculosis in cow bulk tank milk in Cyprus detected by culture and quantitative IS900 and F57 real-time PCR. Prev. Vet. Med. 89(3/4):223226. http://dx.doi.org/10.1016/j.prevetmed.2009.02.020. PMid:19349086.

Smith B.P. 2006. Febre catarral maligna, p.714-716. In: Smith B.P. (Ed.), Medicina Interna de Grandes Animais. 3aㅡ ed. Manole, Barueri, SP.

Souza M.I., Afonso J.A.B., Costa N.A., Coutinho L.T. \& Silva Filho A.P. 2011. Estudo Retrospectivo dos Casos de Obstrução Esofágica por Corpo Estranho em Ruminantes Atendidos na Clínica de Bovinos, Campus Garanhuns/UFRPE, nos anos de 1980-2010. IX Congresso Brasileiro Buiatria, Goiânia, Goiás. Vet. Zootec. 18(4):269.

Thompson J.A., Leite R.M.H., Gonçalves V.S., Leite R.C., Bandeira D.A., Herrmann G.P., Moreira E.C., Prado P.E., Lobato Z.I., Brito C.P. \& Lage A.P. 2006. Spatial and hierarchical variances and age covariances for seroprevalence to Leptospira interrogans serovar hardjo, BoHV-1 and BVDV for cattle in State of Paraiba, Brazil. Prev. Vet. Med. 76(3/4):290-301. http://dx.doi.org/10.1016/j. prevetmed.2006.05.010. PMid:16828906.

Thompson K. 2007. Bones and joints, p.1-184. In: Maxie M.G. (Ed.), Jubb, Kennedy and Palmer's Pathology of Domestic Animals. Vol.1. 5th ed. Elsevier.

Timms V.J., Gehringer M.M., Mitchell H.M., Daskalopoulos G. \& Neilan B.A. 2011. Review. How accurately can we detect Mycobacterium avium subsp. paratuberculosis infection? J. Microbiol. Methods 85(1):1-8. http://dx.doi. org/10.1016/j.mimet.2011.01.026. PMid:21281678.

Torres-Acosta J.F.J. \& Hoste H. 2008. Alternative or improved methods to limit gastro-intestinal parasitism in grazing sheep and goats. Small Rumin. Res. 77(2/3):159-173. http://dx.doi.org/10.1016/j.smallrumres.2008.03.009.

Vilar A.L., Santos C.S., Pimenta C.L., Freitas T.D., Brasil A.W., Clementino I.J., Alves C.J., Bezerra C.S., Riet-Correa F., Oliveira T.S. \& Azevedo S.S. 2015. Herd-level prevalence and associated risk factors for Mycobacterium avium subsp. paratuberculosis in cattle in the State of Paraíba, Northeastern Brazil. Prev. Vet. Med.121(1/2):49-55. http://dx.doi.org/10.1016/j.prevetmed.2015.06.003. PMid:26092721.

Weber M.N., Mósena A.C.S., Simões S.V.D., Almeida L.L., Pessoa C.R.M., Budaszewski R.F., Silva T.R., Ridpath J.F., Riet-Correa F., Driemeier D. \& Canal C.W. 2014. Clinical presentation resembling mucosal disease associated with 'hobi'-like pestivirus in a field outbreak. Transbound Emerg Dis. 63(1):92-100. http:// dx.doi.org/10.1111/tbed.12223. PMid:24735072.

Yamasaki E.M., Brito M.F., Mota R.A., McIntosh D. \& Tokarnia C.H. 2013. Paratuberculose em ruminantes no Brasil. Pesq. Vet. Bras. 33(2):127-140. http://dx.doi.org/10.1590/S0100-736X2013000200001. 